\title{
Endovascular Treatment of Unruptured Intracranial Aneurysms
}

\author{
W. YUE \\ Department of Interventional Radiology, Xinxiang Center Hospital; Xinxiang, Henan, China
}

Key words: intracranial aneurysm, unruptured, embolization

\section{Summary}

We report the clinical and angiographic results of endovascular treatment of unruptured intracranial aneurysms.

Over a three-year period, 80 unruptured aneurysms in 74 patients were electively treated with endovascular management. One aneurysm was diagnosed during investigations for a second ruptured aneurysm, 54 aneurysms were incidentally discovered, 18 aneurysms presented with symptoms of mass effect and seven aneurysms presented with symptoms of brain stem ischemia. Mean size of the 80 unruptured aneurysms was $12.5 \pm 8.0 \mathrm{~mm}$ (range, $2-39 \mathrm{~mm}$ ). Thirty-six aneurysms $(45 \%)$ were small $(<10 \mathrm{~mm})$, 38 aneurysms $(47.5 \%)$ were large $(10-25 \mathrm{~mm})$, and six aneurysms (7.5\%) were giant (25-39 $\mathrm{mm})$. Forty-eight wide-necked aneurysms $(60 \%)$ were coiled with the aid of a supporting device.

The mortality rate was $1.25 \%$, and the overall morbidity was $1.25 \%$. Of these, one of the patients suffered a stroke, leading to severe disability $(1.25 \%)$. In one patient, the aneurysm ruptured during treatment, resulting in death. Initial aneurysm occlusion was complete $(100 \%)$ in $76.25 \%$ aneurysms, nearly complete $(90 \%-98 \%)$ in $10 \%$ aneurysms and incomplete $(60 \%-85 \%)$ in $13.75 \%$ aneurysms. Follow-up angiography was available in 67 patients with 73 treated aneurysms $(91.25 \%)$ from one to 36 months (mean 9.3 months); partial reopening occurred in $7.5 \%$, mainly large and giant aneurysms $(5.5 \%)$. Additional coiling was performed in four aneurysms. There were no complications in additional treatments. At 14.1-month clinical follow-up (range, 2 to 36 months), $m R S$ score was 0 in $78.75 \%$ patients, 1 in $10 \%$ patients, 2 in $8.75 \%$ and 3 in $1.25 \%$. There was no aneurysmal rup- ture during the follow-up period. Endovascular treatment of unruptured intracranial aneurysms has low procedural mortality and morbidity rates.

\section{Introduction}

Intracranial aneurysms may present with subarachnoid hemorrhage, the most feared complication of intracranial aneurysms, but most commonly they are detected on brain imaging performed for reasons unrelated to the intracranial aneurysms ${ }^{1}$. Once detected, the management decision is complex and dependent on the natural history of the unruptured intracranial aneurysm ${ }^{2}$. The management of unruptured intracranial aneurysms remains controversial because of a lack of understanding of the natural history of intracranial aneurysms ${ }^{3-9}$. This study reports our clinical and angiographic outcomes in 74 patients treated endovascularly.

\section{Patients and Methods}

Between January 2008 and January 2011 1671 aneurysms were treated endovascularly in our center. Of these, 1554 aneurysms had ruptured and 117 had not. Of the 117 unruptured aneurysms, 37 were not treated, and the remaining 80 aneurysms in 74 patients were treated electively. Of the 74 patients, six had more than one unruptured aneurysm treated in a single session (with two unruptured aneurysms). In general, endovascular management was offered as a first treatment option in all large and giant aneurysms, all posterior circula- 
tion aneurysms, and all carotid artery aneurysms. Patients with aneurysms on the middle cerebral artery and anterior communicating artery were offered coiling when a defined neck was present.

The 74 patients with 80 endovascularly treated unruptured aneurysms are the subject of the present study. There were 41 women $(51.25 \%)$ and 39 men $(48.75 \%)$ with a mean age of $49 \pm 12.5$ years (range, 13-69-years). Seventeen patients $(21.25 \%)$ were older than 60 years of age. Of 80 aneurysms, one was diagnosed during investigations for a second ruptured aneurysm. Fifty-four aneurysms were incidentally discovered on imaging studies performed for clinical reasons unrelated to the presence of the aneurysm. Eighteen aneurysms presented with symptoms of mass effect: ophthalmoplegia, eight; visual disorders, six; brain stem compression, four. Seven aneurysms presented with symptoms of brain stem ischemia. Twenty-nine of $80(36.25 \%)$ aneurysms were located in the posterior circulation: vertebral artery-inferior cerebellar arteries, 16; basilar trunk, six; vertebobasilar junction, four; posterior cerebral artery, three. Fifty-one $(63.75 \%)$ aneurysms were located in the anterior circulation: anterior communicating artery, one; distal anterior cerebral artery, one; pericallosal artery, one; ophthalmic segment of internal carotid artery, 25; cavernous sinus, 14; middle cerebral artery, four; posterior communicating artery, five. Mean size of the 80 unruptured aneurysms was $12.5 \pm 8.0 \mathrm{~mm}$ (range, $2-39 \mathrm{~mm}$ ). Thirty-six aneurysms $(45 \%)$ were small $(<10 \mathrm{~mm}), 38$ aneurysms $(47.5 \%)$ were large $(10-24 \mathrm{~mm})$, and six aneurysms $(7.5 \%)$ were giant $(25-39 \mathrm{~mm})$.

\section{Endovascular Management}

Endovascular management of aneurysms was performed under general anesthesia and systemic heparinization. Coil embolization was performed with Guglielmi Detachable Coils (GDC; Boston Scientific, Fremont, CA, USA), TruFill DCS coils (Cordis, Miami Lakes, FL, USA) or Microplex coils (Microplex, Microvention, Aliso Viejo, CA, USA). The aim of coiling was to pack the aneurysm as densely as possible, until not a single additional coil could be placed. Complications of coiling were recorded. The initial procedural outcome was categorized as the following: complete occlusion $(100 \%)$, nearly complete $(>90 \%)$ and incomplete $(\leq 90 \%)^{10}$.

\section{Adjunct Management}

Five wide-necked aneurysms were coiled with a temporary supporting balloon (Hyperglide; M.T.I.-ev3, Calif, USA), and 43 widenecked aneurysms were managed using placement of a stent (29 Enterprise stents, Cordis, Miami Lakes, FL, USA; seven Neuroform and two Wingspan stents, Boston Scientific and five Leo stents, Balt, Montmorency, FR) with additional coil embolization in 38 aneurysms.

\section{Medication}

All of the patients were treated with heparin during the procedure. Typically, heparin administration, with the aim of achieving measured activated clotting times of 220-250 seconds, was initiated after the first coil or coils had been deployed and the ruptured aneurysm was considered to be stable. Combination therapy with clopidogrel (a loading dose of $300 \mathrm{mg}$, and 75 $\mathrm{mg}$ daily for one to three months thereafter) and aspirin (a loading dose of $300 \mathrm{mg}$, and 100 mg daily for one to six months) was started two hours before the procedure in all patients.

\section{Clinical and Angiographic Follow-up}

The outcome according to the modified Rankin Scale Score 11 was evaluated at 14.1-month follow-up (range 2-36 months). Follow-up angiograms were performed after one to 36 months (mean 9.3 months). Results of follow-up angiography were classified in the same way as for initial angiographic results.

\section{Results}

\section{Angiographic and Clinical Results and Follow-up}

Initial aneurysm occlusion was complete $(100 \%)$ in 61 aneurysms $(76.25 \%)$, nearly complete $(90 \%-100 \%)$ in eight aneurysms $(10 \%)$, and incomplete $(<90 \%)$ in 11 aneurysms $(13.75 \%)$. Angiographic follow-up was performed in 67 patients with 73 treated aneurysms $(91.25 \%)$ from one to 36 months (mean 9.3 months). Follow-up angiography was not available in seven patients with seven treated aneurysms. One patient with one treated basilar trunk aneurysm died from procedural complications of coiling. Partial reopening of the coiled aneurysm occurred in six out of 80 aneu- 
rysms $(7.5 \%)$ in six patients. Mean size of these reopened aneurysms was $19 \mathrm{~mm}$ (range, 6-34 $\mathrm{mm})$, and four out of six (66.7\%) reopened aneurysms were large or giant. Additional coil embolization was performed in four aneurysms. Two partially reopened aneurysms were left untreated because the anatomy precluded additional coiling. There were no complications of additional treatments. At 14.1-month clinical follow-up (range, 2 to 36 months), mRS score was zero in $78.75 \%$ patients, one in $10 \%$ patients, two in $8.75 \%$ and three in $1.25 \%$. There was no aneurysmal rupture during the followup period.

\section{Effect of Endovascular Management on Neurological Deficits}

Clinical follow-up was available in 17 patients with aneurysms presenting with symptoms of mass effect and seven patients presented with symptoms of brain stem ischemia. Of these 24 patients, mRS scores was 0 in ten patients, 1 in eight patients, 2 in five and 3 in one at final clinical follow-up.

\section{Complications}

Complications of coiling occurred in three patients. Of these, one patient died and another suffered a permanent neurologic deficit. Mortality of coiling was $1.25 \%$ and permanent morbidity was $1.25 \%$. The patient with permanent morbidity was mRS 3 .

\section{Discussion}

We found that endovascular therapy is an attractive option for treatment of unruptured aneurysms. This method of treatment is safe with a low rate of complications in a large consecutive series of aneurysms with high proportions of symptomatic unruptured aneurysms, large and giant size, location in the posterior circulation, and treatments with technically challenging neck supporting devices. Our results are in the same range as previously published reports on endovascular treatment; in a systematic review of 30 studies comprising 1397 unruptured aneurysms treated with detachable coils, mortality was $0.6 \%$ and morbidity was $7 \%{ }^{12}$. Although direct comparison may not be valid because of differences in patient and aneurysm characteristics, procedural com- plications are also in the same range as for series of endovascularly treated unruptured aneurysms. A 5044-patient meta-analysis conducted by Naggara et al. ${ }^{5}$ reported a procedural unfavorable outcome in $4.8 \%$ and immediate angiographic results showed satisfactory occlusion in $86.1 \%$. Recurrences were shown in $24.4 \%$ and retreatment was needed in $9.1 \%$. The annual risk of bleeding after endovascular treatment was $0.2 \%$. On the other hand, there is growing evidence that endovascular treatment carries lower risks than surgical treatment for unruptured aneurysms. A study conducted by Alshekhlee et al. ${ }^{6}$ showed that the length of hospital stay was longer in the clipped population (median four versus one day; $\mathrm{P}<0.0001)$. Mortality was higher in the clipped population: $(1.6 \%$ versus $0.57 \%$; odds ratio 3.63). Perioperative intracerebral hemorrhage and acute ischemic stroke were higher in the clipped population. A direct comparison of surgical versus endovascular repair of unruptured aneurysms in 118 patients by Johnston et al. ${ }^{13}$ found that $25 \%$ of patients in the surgical group developed a change in Rankin Scale score of 2 or more versus $8 \%$ of endovascular patients. However, another study reported by Gerlaeh et al. ${ }^{14}$ showed that $6.4 \%$ of the surgical and $7.7 \%$ of the endovascular patients had new neurological deficits immediately after treatment, mainly related to cerebral ischaemia. After six months, three $(2.3 \%)$ patients had a treatment-related unfavourable outcome, defined as mRS $>2$, two patients after surgical and one patient after endovascular aneurysm repair (not statistically different, $\mathrm{p}=$ 0.3 ; Fisher's exact test). The rate of recanalization of unruptured intracranial aneurysms is higher after endovascular obliteration. In another study 15 the primary treatment modality was surgical in 2,357 cases and endovascular in 255 cases. Adverse outcomes were significantly more common in surgical cases $(18.5 \%)$ compared to endovascular cases $(10.6 \%) \quad(p=$ 0.002 ), and the difference was not altered after adjusting for age, sex, race, transfer admissions, emergency room admissions, and year of treatment (odds ratio [OR] 2.1, 95\% confidence interval $[\mathrm{CI}] 1.4$ to $3.3 ; \mathrm{p}=0.001$ ). In-hospital mortality was also increased in surgical cases ( $2.3 \%$ versus $0.4 \% ; p=0.039)$, but the difference was not significant in the multivariable model (OR 6.3, 95\% CI 0.9 to 46.1; $\mathrm{p}=0.07$ ). Length of stay and hospital charges were significantly greater for surgical cases. 
The natural history of unruptured intracranial aneurysms is still unclear. The study by Wiebers et al. ${ }^{16}$ reported five-year cumulative rupture rates for patients who did not have a history of subarachnoid hemorrhage with aneurysms located in internal carotid artery, anterior communicating or anterior cerebral artery, or middle cerebral artery of $0 \%, 2.6 \%, 14.5 \%$, and $40 \%$ for aneurysms less than $7 \mathrm{~mm}, 7-12$ $\mathrm{mm}, 13-24 \mathrm{~mm}$, and $>25 \mathrm{~mm}$, respectively, compared with rates of $2.5 \%, 14.5 \%, 18.4 \%$, and $50 \%$, respectively, for the same size categories involving posterior circulation and posterior communicating artery aneurysms. On the other hand, adverse outcomes after surgery or coiling of unruptured aneurysms were in the range of $25 \%$ and $10 \%$, respectively 16 . A report by $\mathrm{Ju}-$ vela et al ${ }^{17}$, recently republished in the Journal of Neurosurgery showed the annual incidence of SAH for unruptured intracranial aneurysm was $1.3 \%$ and the cumulative rate of bleeding was $10.5 \%$ at ten years, $23 \%$ at 20 years, and $30.3 \%$ at 30 years after diagnosis. The diameter of the unruptured aneurysm (relative risk [RR] 1.11 per $\mathrm{mm}$ in diameter, $95 \%$ confidence interval $[\mathrm{CI}] 1-1.23, \mathrm{p}=0.05$ ) and patient age at diagnosis inversely (RR 0.97 per year, $95 \%$ CI $0.93-1, p=0.05$ ) were significant independent predictors for a subsequent aneurysm rupture after adjustment for sex, hypertension, and aneurysm group. Active smoking status at the time of diagnosis was a significant risk factor for aneurysm rupture (RR 1.46, 95\% CI 1.04$2.06, \mathrm{p}=0.033$ ) after adjustment for size of the aneurysm, patient age, sex, presence of hypertension, and aneurysm group. Active smoking status as a time-dependent covariate was an even more significant risk factor for aneurysm rupture (adjusted RR 3.04, 95\% CI 1.21-7.66, p $=0.02$ ). Tsukahara et al.'s study 18 observed 209 aneurysms in 181 cases without surgical treatment showing that these aneurysms gave a rupture rate of $3.42 \% / y e a r$. In a recent review, Komotar et al. ${ }^{19}$ made several recommendations: 1) with rare exceptions, all symptomatic unruptured aneurysms should be treated; 2) small, incidental aneurysms less than $5 \mathrm{~mm}$ in diameter should be managed conservatively in virtually all cases; 3 ) aneurysms larger than $5 \mathrm{~mm}$ in patients younger than 60 years of age should be seriously considered for treatment; 4) large, incidental aneurysms larger than $10 \mathrm{~mm}$ should be treated in nearly all patients younger than 70 years of age; and 5) microsurgical clipping rather than endovascular coiling should be the first treatment choice in low-risk cases. Several studies on endovascular coil embolization have been published 7,8,20-26. Complete or nearly complete occlusion of the aneurysms was achieved in $82 \%-96.1 \%$ and the morbidity and mortality related to endovascular management of unruptured intracranial aneurysms were $0.27 \%-7.7 \%$ and $0 \%-1.7 \%$ 7,8,20-26. These data have to be considered in balancing the risk of rupture against the risk of complications of elective treatment in patients presenting with unruptured aneurysms. Higashida et al. ${ }^{27}$ evaluated 2535 surgically and endovascularly treated unruptured cerebral aneurysms, endovascular treatment was associated with fewer adverse outcomes $(6.6 \%$ versus $13.2 \%)$, decreased mortality $(0.9 \%$ versus $2.5 \%)$, shorter lengths of stay (4.5 versus 7.4 days), and lower hospital charges (42,044 dollars versus 47,567 dollars) compared with neurosurgical treatment $(\mathrm{P}<$ .05 ). After multivariable adjustment, neurosurgical cases had $70 \%$ greater odds of an adverse outcome, $30 \%$ increased hospital charges, and $80 \%$ longer length of stay compared with endovascular cases $(\mathrm{P}<.05)$. In our opinion, when treatment of an unruptured intracranial aneurysm is considered, endovascular therapy should be the first treatment option. When an aneurysm is unsuitable for endovascular treatment, surgical treatment may be considered as an alternative.

\section{Conclusion}

Endovascular therapy appears to be an attractive option for treatment of unruptured aneurysms. This method of treatment is safe with a low rate of complications. Endovascular therapy, as a treatment alternative to surgical clipping, should be offered as a viable therapeutic option for all patients considering treatment of an unruptured cerebral aneurysm. 


\section{References}

1 Brown RD. Unruptured intracranial aneurysms. Semin Neurol. 2010; 30: 537-544.

2 Bederson J, Awad I, Wiebers D, et al. Recommendations for the management of patients with unruptured intracranial aneurysms. Stroke. 2000; 31: 2742-2750.

3 Raymond J, Roy D, Weill A, et al. Trial on Endovascular Aneurysm Management (TEAM) collaborative group Unruptured intracranial aneurysms: their illusive natural history and why subgroup statistics cannot provide normative criteria for clinical decisions or selection criteria for a randomized trial. J Neuroradiol. 2008; 35: 210-216.

4 Raymond J, Nguyen T, Chagnon M, et al. Trial on Endovascular Aneurysm Management (TEAM) collaborative group. Unruptured intracranial aneurysms. opinions of experts in endovascular treatment are coherent, weighted in favour of treatment, and incompatible with ISUIA. Interv Neuroradiol. 2007; 13: 225-237.

5 Naggara ON, White PM, Guilbert F, et al. Endovascular treatment of intracranial unruptured aneurysms: systematic review and meta-analysis of the literature on safety and efficacy. Radiology. 2010; 256: 887-897.

6 Alshekhlee A, Mehta S, Edgell RC, et al. Hospital mortality and complications of electively clipped or coiled unruptured intracranial aneurysm. Stroke. 2010; 41: 1471-1476.

7 Pierot L, Spelle L, Leclerc X, et al. Endovascular treatment of unruptured intracranial aneurysms: comparison of safety of remodeling technique and standard treatment with coils. Radiology. 2009; 251: 846-855.

8 Im SH, Han MH, Kwon OK, et al. Endovascular coil embolization of 435 small asymptomatic unruptured intracranial aneurysms: procedural morbidity and patient outcome. Am J Neuroradiol. 2009; 30: 79-84.

9 Gallas S, Drouineau J, Gabrillargues J, et al. Feasibility, procedural morbidity and mortality, and long-term follow-up of endovascular treatment of 321 unruptured aneurysms. Am J Neuroradiol. 2008; 29: 63-68.

10 Kang HS, Han MH, Kwon BJ, et al. Short-term outcome of intracranial aneurysms treated with polyglycolic acid/ lactide copolymer-coated coils compared to historical controls treated with bare platinum coils: a singlecenter experience. Am J Neuroradiol. 2005; 26: 1921-1928.

11 Van Swieten J, Koudstaal P, Visser M, et al. Interobserver agreement for the assessment of handicap in stroke patients. Stroke. 1988; 19: 604-607.

12 Lanterna LA, Tredici G, Dimitrov BD, et al. Treatment of unruptured cerebral aneurysms by embolization with Guglielmi detachable coils: case-fatality, morbidity, and effectiveness in preventing bleeding-a systematic review of the literature. Neurosurgery. 2004; 55: 767-775.

13 Johnston SC, Wilson C, Halbach V, et al. Endovascular and surgical treatment of unruptured cerebral aneurysms: comparison of risks. Ann Neurol. 2000; 4: 11-19.

14 Gerlach R, Beck J, Setzer M, et al. Treatment related morbidity of unruptured intracranial aneurysms: results of a prospective single centre series with an interdisciplinary approach over a 6 year period (1999-2005). J Neurol Neurosurg Psychiatry. 2007; 78: 864-871.

15 Johnston SC, Dudley RA, Gress DR, et al. Surgical and endovascular treatment of unruptured cerebral aneu- rysms at university hospitals. Neurology. 1999; 52: 17991805.

16 Wiebers DO, Whisnant JP, Huston J $3^{\text {rd }}$, et al. International Study of Unruptured Intracranial Aneurysms Investigators. Unruptured intracranial aneurysms: natural history, clinical outcome, and risks of surgical and endovascular treatment. Lancet. 2003; 362: 103-110.

17 Juvela S, Porras M, Poussa K . Natural history of unruptured intracranial aneurysms: probability of and risk factors for aneurysm rupture. J Neurosurg. 2008; 108: 1052-1060.

18 Tsukahara T, Murakami N, Sakurai Y, et al. Treatment of unruptured cerebral aneurysms; a multi-center study at Japanese national hospitals. Acta Neurochir Suppl. 2005; 94: 77-85.

19 Komotar RJ, Mocco J, Solomon RA. Guidelines for the surgical treatment of unruptured intracranial aneurysms: the first annual J. Lawrence pool memorial research symposium-controversies in the management of cerebral aneurysms. Neurosurgery. 2008; 62: 183-194.

20 Park HK, Horowitz M, Jungreis C, et al. Periprocedural morbidity and mortality associated with endovascular treatment of intracranial aneurysms. Am J Neuroradiol. 2005; 26: 506-514.

21 Terada T, Tsuura M, Matsumoto H, et al. Endovascular treatment of unruptured cerebral aneurysms. Acta Neurochir Suppl. 2005; 94: 87-91.

22 Grunwald IQ, Papanagiotou P, Politi M, et al. Endovascular treatment of unruptured intracranial aneurysms: occurrence of thromboembolic events. Neurosurgery. 2006; 58: 612-618.

23 van Rooij WJ, Sluzewski M . Procedural morbidity and mortality of elective coil treatment of unruptured intracranial aneurysms. Am J Neuroradiol. 2006; 27: 16781680.

24 Gallas S, Drouineau J, Gabrillargues J, et al. Feasibility, procedural morbidity and mortality, and long-term follow-up of endovascular treatment of 321 unruptured aneurysms. Am J Neuroradiol. 2008; 29: 63-68.

25 Standhardt H, Boecher-Schwarz H, Gruber A, et al. Endovascular treatment of unruptured intracranial aneurysms with Guglielmi detachable coils: short- and longterm results of a single-centre series. Stroke. 2008; 39: 899-904.

26 Im SH, Han MH, Kwon OK, et al. Endovascular coil embolization of 435 small asymptomatic unruptured intracranial aneurysms: procedural morbidity and patient outcome. Am J Neuroradiol. 2009; 30: 79-84.

27 Higashida RT, Lahue BJ, Torbey MT, et al. Treatment of unruptured intracranial aneurysms: a nationwide assessment of effectiveness. Am J Neuroradiol. 2007; 28: 146-151.
Wentao Yue, MD

Department of Interventional Radiology Xinxiang Center Hospital

Xinxiang, 453000, Henan, China

E-mail: ywt999999@126.com 